That cortisone may be of value in the treatment of Schüller-Christian's disease was suggested by Blahd, Levy and Bassett (1951). In the present case prednisone may have been of temporary benefit. The maximal effect was on the lymph glands. Although the mandibular lesion continued to improve this was probably due to the radiotherapy as no decrease in size was noted in the other bony lesion.

A purulent discharge from the ear is frequently mentioned in previous case reports and this is often associated with the presence of granulation tissue in the external auditory canal. It has not been considered of much importance but it is so common a finding that it must form part of the clinical picture. Histological examination of the granulations in this case identified the tissue as being similar to the lesions elsewhere in the patient.

Anæmia is a common finding in this disease and its occurrence has not been completely explained. At post-mortem examination in this case, granulomatous deposits were found in the bone marrow but they were not so extensive as to completely replace the blood forming elements. That the bone marrow is capable of responding even when involved in the disease process was demonstrated by Wallgren (1940) who found a reticulocyte count of $12.6 \%$ in a patient with a hæmoglobin of $32 \%$. The failure to respond to blood transfusion was surprising but this type of progressive anæmia in spite of blood replacement has been reported (Abt and Denenholz, 1936). In this case obvious hæmolysis of the red cells was taking place. It may be that a hæmolytic type of anæmia is usually present in this disease. However, no reference to this can be found in the literature.

I am indebted to Mr. M. H. Harmer for permission to publish this case report.

\section{REFERENCES}

ABT, A. F., and DenenholZ, E. J. (1936): LettererSiwe's Disease. Splenohepatomegaly Associated with Widespread Hyperplasia of Non-lipoid Storing Macrophages; Discussion of the so-called Reticulo-endotheliosis. Amer. J. Dis. Child., 51, 499.

BlaHD, W. H., Levy, M. S., and Bassett, S. H. (1951): A Case of Hand-Schüller-Christian Syndrome treated with Cortisone. Ann. intern. Med., 35, 927.

FARBER, S. (1941): The Nature of "Solitary or 8 Eosinophilic Granuloma" of Bone. Amer. J. Path., 3 . 17, 625.

GreEN, W. T., and FARBER, S. (1942): "Eosinophilic or Solitary Granuloma" of Bone. J. Bone Jt. Surg., 24, 499.

JAFFE, H. L., and LiCHTENSTEIN, L. (1944): Eosino- \&ै philic Granuloma of Bone. Arch. Path., 37, 99.

LICHTENSTEIN, L. (1953) : Histiocytosis X. Integration of Eosinophilic Granuloma of Bone, "LettererSiwe disease", and "Schüller-Christian disease" as TT related Manifestations of a Single Nosologic Entity. A.M.A. Arch. Path., 56, 84.

MCGavRan, M. H., and SPADY, H. A. (1960): Eosinophilic Granuloma of Bone, J. Bone Jt Surg 42A, 979.

WALlGREN, A. (1940): Systemic Reticuloendothelia Granuloma. Non-lipoid Reticuloendotheliosis and Schüller-Christian Disease. Amer. J. Dis. Child ج⿱ 60, 471 .

\title{
ARTERIAL OCCLUSION TREATED WITH STREPTOKINASE
}

\author{
A Report of Two Cases
}

M. L. Clark, M.B., M.R.C.P.

Margaret Howell, M.B., B.S.

\author{
Christine Hawkey, M.Sc. \\ R. S. O. REES, M.B., M.R.C.P., D.M.R.D.
}

J. StubBs, Ph.D., F.R.C.S.

St. George's Hospital and Medical School, London, S.W.1.

The Plasminogen activator streptokinase was first given intravenously to human volunteers by Tillett, Johnson and McCarty (1955) and subsequently has been used as a thrombolytic agent, case reports having recently been published in British journals (Cotton, Flute and Tsapogas, 1962; McNicol, Reid, Bain, and Douglas, 1963; Verstræte, Amery and Vermylen, 1963). Streptokinase may be administered by one of two methods; either intravenous infusion starting with a calculated loading dose, thus providing a high level of streptokinase throughout the circulation, or by local infusion into the affected artery proximal to the actual occlusion. The second method has the advantage that, whilst using relatively small doses, a high concentration of the drug can be brought into close contact with the thrombus, although the level of streptokinase in the general circulation remains too low to cause a coagulation defect. 


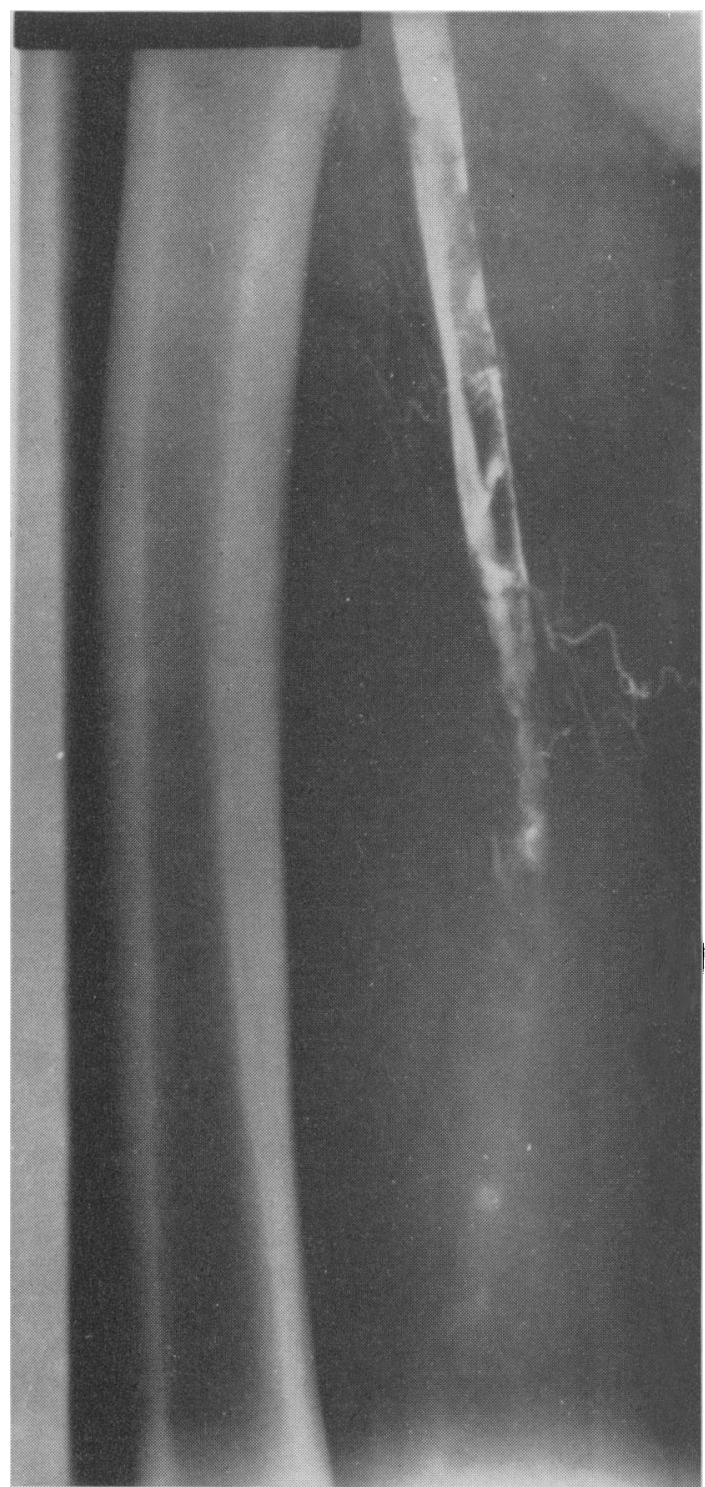

Fig. 1.-Femoral arteriogram immediately before Streptokinase infusion.

We wish to report the treatment with streptokinase of two cases of arterial occlusion, one by local infusion and the other by general intravenous therapy. The second case is of particular interest because firstly there was evidence that thrombolysis was still occurring 96 hours after the initial occlusion, and secondly continuous treatment was maintained for seven days.

\section{Materials and Methods}

The streptokinase used was a highly purified preparation 'Kabikinase' supplied by Kabi Pharmaceuticals, London. The SK units referred to are

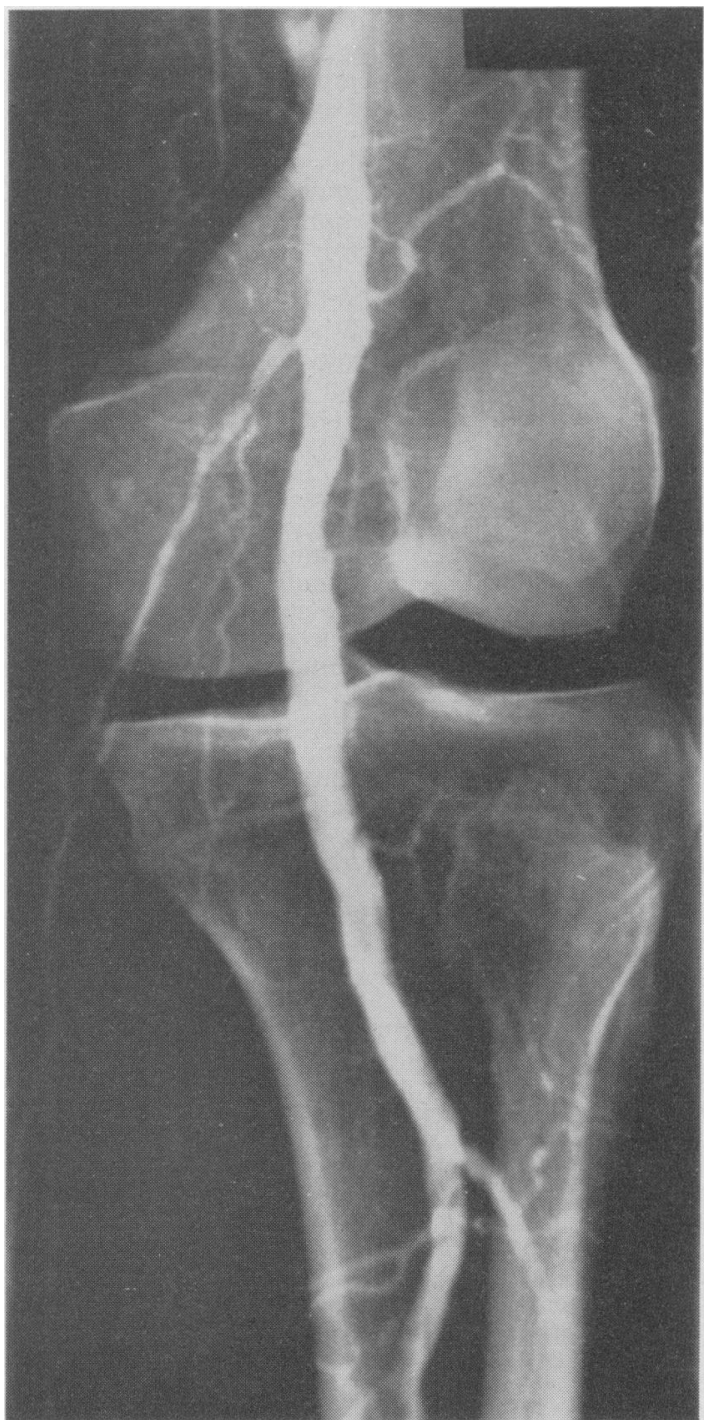

FIG. 2.-Femoral arteriogram after $17 \frac{1}{2}$ hours infusion of Streptokinase.

"Manufacturer's" units. In each case samples of venous blood were collected before and at intervals during the infusion. The following tests were carried out immediately on all samples: euglobulin lysis time, strong thrombin time (50 N.I.H. units thrombin $/ \mathrm{ml}$.), weak thrombin time (5 N.r.H. units thrombin $/ \mathrm{ml}$.) and prothrombin time, and, in addition, an antistreptokinase antibody titration was performed on the initial sample from Case 2. Plasma was stored at $-35^{\circ} \mathrm{C}$. for fibrinogen and plasminogen assays to be carried out at a later date. The methods for collecting the blood samples and carrying out the above tests are described elsewhere (Hawkey and Howell, 1964). 
Case No. 1

The patient was a 67-year-old man who nine days after admission to hospital with a left hemiparesis complained of coldness in the left leg and foot, no pulse being palpable below the left femoral. By the next day there was no improvement and the limb had become cyanosed and mottled over its anterior aspect. A catheter was inserted into the left femoral artery percutaneously by the Seldinger technique and advanced into the thigh under fluoroscopic control. Slight resistance was encountered at about $10 \mathrm{~cm}$. so $5 \mathrm{ml}$. of Isopaque was injected and a film exposed (Fig. 1). The medium was seen to enter blood clot, the artery being completely blocked just distal to the catheter tip. With the catheter in this position a continuous infusion of streptokinase was administered using a mechanically driven syringe-driver.

The infusion which was started approximately 29 hours after the onset of symptoms was continued for $25 \frac{3}{4}$ hours, a total of 731,000 units of streptokinase being given. There was no loading dose and the initial rate of infusion was 700 units in $0.5 \mathrm{ml}$. physiological saline per minute. After 15 hours this was reduced to 350 units/minute because of evidence of high systemic fibrinolytic activityy (Table 1) and four hours later it was reduced further to 250 units per minute. Conventional anticoagulant therapy with pheninidione was started 12 hours after the infusion began. No reaction attributable to the streptokinase occurred during the infusion, the patient's temperature remaining at the pre-infusion level throughout.

Soon after starting treatment the upper thigh became warm; the popliteal pulse returned within 14 hours and an arteriogram at that time showed filling to the upper part of the popliteal artery although the arterial walls appeared to be very irregular. The catheter was advanced down the thigh, closer to the point of occlusion, and the infusion continued. A further arteriogram $3 \frac{1}{2}$ hours later showed a relatively normal popliteal with good filling of the proximal parts of the tibial arteries (Fig. 2). The leg continued to improve clinically and when the infusion was discontinued after a total of $25 \frac{3}{4}$ hours, the entire limb, apart from the lower part of the dorsum of the foot, was warm. Desquamation of the skin of the lower leg occurred during the next 14 days but when seen in the outpatient department three months later the leg appeared normal and all pulses, except the dorsalis pedis, were present. There were residual signs of hemiparesis, motor function being slightly impaired, but there was no sensory loss.

\section{Case No. 2}

A 67-year-old woman with atrial fibrillation developed a complete right hemiplegia. Ten days later she complained of pain in the left leg which was found to be cold with no pulse palpable. Sensation was normal but she was only able to move her toes. A diagnosis of embolic occlusion of the limb was made and anticoagulation with heparin and phenindione was started. The following day there was no improvement, the leg being very painful with no voluntary movement possible and diminished cutaneous sensation. Streptokinase therapy was started 34 hours after the onset of symptoms, $S p$. herapin being discontinued and $100 \mathrm{mg}$. hydrocortisone hemisuccinate given: phenindione was continued throughout the infusion. A loading dose of 200,000 units of streptokinase, calculated from the antistreptokinase antibody titration and the patient's body weight, was given in $40 \mathrm{ml}$. $5 \%$ dextrose over a period of
TABLE 1

Investigations on Plasma Samples from Case 1

\begin{tabular}{|c|c|c|c|c|c|}
\hline & & & & \multicolumn{2}{|c|}{ Post Infusion } \\
\hline Hours of infusion & 0 & 15 & 21 & $1 \frac{1}{2}$ & 12 \\
\hline time (minutes) & 130 & 13 & 8 & 35 & \\
\hline $\begin{array}{l}\text { Prothrombin time } \\
\text { (seconds) }\end{array}$ & 16 & 21 & 18 & - & \\
\hline $\begin{array}{l}\text { Thrombin time } \\
\text { (seconds) }\end{array}$ & & & & & \\
\hline $\begin{array}{r}50 \text { units } / \mathrm{ml} \text {. } \\
5 \text { units } / \mathrm{ml} \text {. }\end{array}$ & $\begin{array}{r}8 \\
37\end{array}$ & $\begin{array}{c}25 \\
\text { no clot } \\
\text { formed }\end{array}$ & $\begin{array}{r}18 \\
180\end{array}$ & 二 & - \\
\hline $\begin{array}{l}\text { Fibrinogen } \\
\text { mg./100 ml. }\end{array}$ & 156 & 84 & 120 & 150 & 198 \\
\hline
\end{tabular}

30 minutes into an antecubital vein. This was followed by a sustaining dose of 50,000 units of streptokinase in $30 \mathrm{ml}$. dextrose per hour, and this infusion rate was continued for seven days with only minor adjustments. During this period a total is of 7,000,000 units of streptokinase was given. Results $N$ of the investigations carried out on the patient's plasma are shown in Figure 3. There was no deleterious reaction during the infusion which could be attributed to the streptokinase.

Within two hours of starting the infusion the upper third of the thigh had become warm and this improvement continued slowly over the following days until the limb was warm to the level of the knee, the femoral pulse becoming palpable for the first time 96 hours after the onset of symptoms. There was little further improvement, the warm area finally extending to just below the knee with the leg dista to this showing gangrenous changes. On the sixt day of the streptokinase infusion $1000 \mathrm{ml}$. of low molecular weight dextran was given (Rheomacrodex, Pharmacia Ltd.-10\% solution in dextrose). The patient's general condition gradually deteriorated and she died 25 days after the arterial occlusion. Permission for post-mortem examination was not given.

\section{Discussion}

The excellent result achieved in Case 1 was almost certainly due to thrombolytic therapy being started relatively soon after the occlusion. Not only was the limb still viable but the thrombus was still susceptible to lysis. The work of Johnson and McCarty (1959) suggests that the susceptibility of an intravascular thrombus to lysis lessens as it becomes older. These workers also noted that artificially induced clots in the forearm veins of volunteers could only be removed by SK infusion for up to 72 hours after their formation. In Case 2 the return of the femoral pulse 96 hours after the onset of symptoms of occlusion suggests that thrombolysis was c still proceeding at this time. Two possible $N$ explanations for this are that artificially induced clots may differ from spontaneous intravascular thrombi in their susceptibility to SK, and that after embolic occlusion of the artery further $O$ clotting may have occurred slowly below the block so that younger thrombus was present? distally.

The percutaneous method of arterial catheterisation used in Case 1 simplifies infusion and 

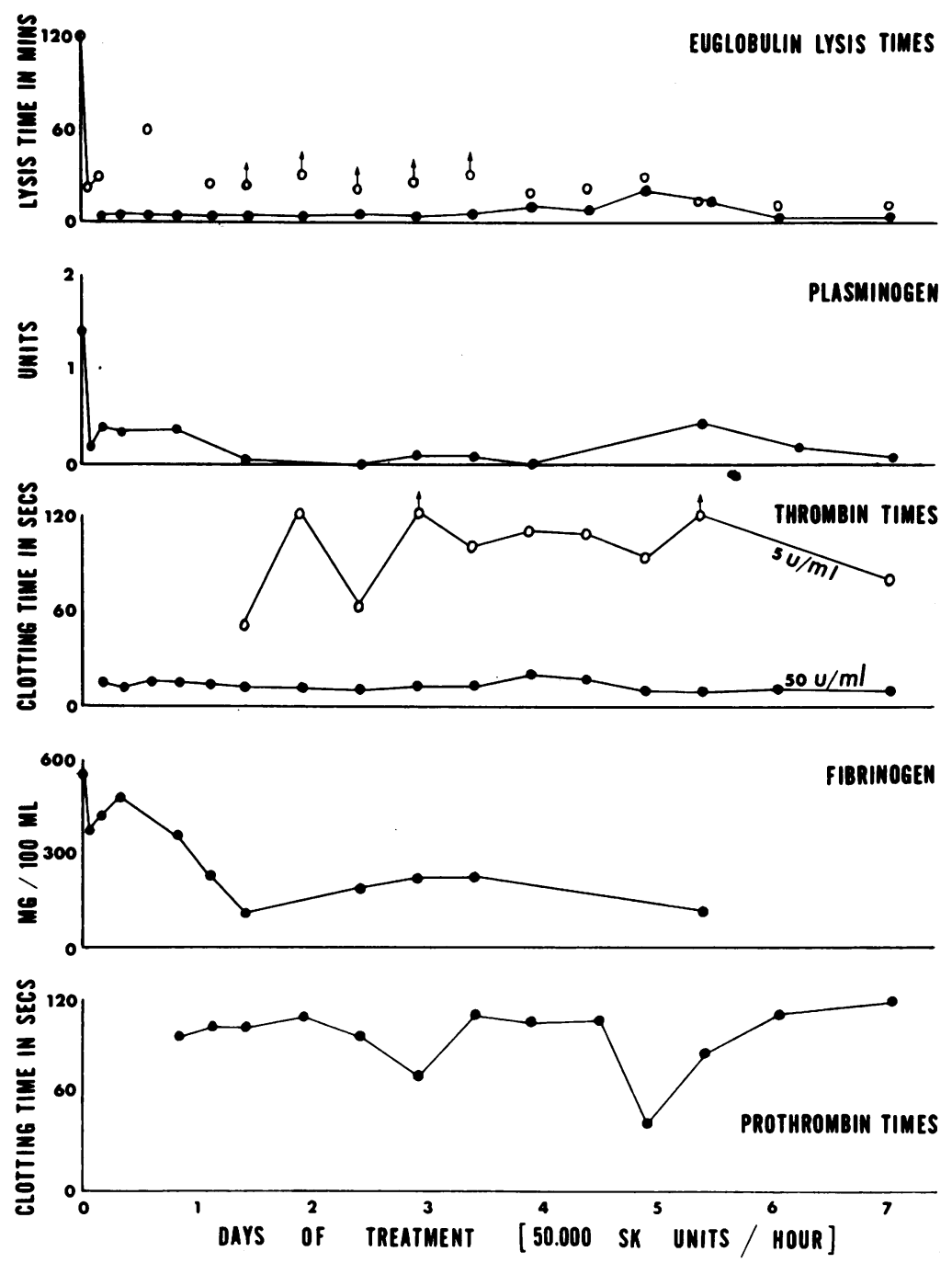

FIG. 3.-Investigations on plasma samples from Case 2. Arrows indicate tests which were not followed for longer than times plotted. Euglobulin lysis times with added plasminogen are shown as solid circles (top graph).

permits serial arteriograms to be taken. These indicate the progress of lysis, enable the catheter to be advanced closer to the occlusion and help the duration of the infusion to be determined. The fact that there was some restoration of circulation in Case 2 shows that continuous systemic therapy is also effective and can be maintained for up to seven days without complication, so long as there is no coincidental cause for hæmorrhage.

\section{Summary}

Thrombolysis induced by streptokinase infusion is reported in two elderly patients with embolic arterial occlusion.

In the first case local intra-arterial infusion was started 29 hours after a mid-femoral block. Distal pulsation returned after 14 hours infusion and an excellent result was ultimately achieved. In the second case, systemic streptokinase therapy was begun 36 hours after occlusion of an iliac artery: although recovery was only partial systemic treatment was maintained for seven days without complication and the femoral pulse returned 96 hours after the onset of symptoms.

The advantages of local percutaneous infusion controlled by serial angiography are commented upon. 
We are grateful to Dr. J. Dow and Mr. J. Gillespie for their permission to report these cases.

We would like to thank Miss Noel Lansdown and Mr. V. Elliott for their expert technical assistance.

We are particularly grateful to $\mathrm{Mr}$. A. M. Nicholls of Kabi Pharmaceuticals for generous supplies of Kabikinase.

This work was supported by grants from the St. George's Hospital Research Fund and the Medical Research Council.

\section{REFERENCES}

Cotton, L. T., Flute, P. T., and Tsapogas, M. J. C. (1962): Popliteal Artery Thrombosis treated with Streptokinase, Lancet, ii, 1081.

HAWkeY, C. M., and Howell, M. B. (1964): The Laboratory Control of Thrombolytic Therapy, $J$. clin. Path., 17, 287.
Johnson, A. J., and McCARTY, W. R. (1959): The Lysis of Artificially Induced Intravascular Clots in Man by Intravenous Infusions of Streptokinase, $₫$ J. clin. Invest., 38, 1627.

MCNicol, G. P., ReID, W., BAIN, W. H., and $\overrightarrow{\vec{F}}$ Douglas, A. S. (1963): Treatment of Peripheral Arterial Occlusion by Streptokinase Perfusion, Brit. med. J., i, 1508.

Tillett, W. S., Johnson, A. J., and MCCARTY, W. R. $\frac{\bar{T}}{\Phi}$ (1955): Intravenous Infusion of the Streptococcal $\varrho$ Fibrinolytic Principle (Streptokinase) into Patients: J. clin. Invest., 34, 169.

Verstraete, M., Amery, A., and Vermylen, J. (1963): Feasibility of Adequate Thrombolytic $\overrightarrow{\vec{c}}$ Therapy with Streptokinase in Peripheral Arteria! o Occlusions, Brit. med. J., i, 1499.

\title{
CROHN'S DISEASE OF THE STOMACH?
}

\author{
G. A. KunE, M.B., F.R.C.S., F.R.A.C.S.*, \\ Senior Surgical Registrar. \\ Jane Fullerton, M.B., B.Ch., D.P.H., F.C.Path., \\ Consultant Pathologist.
}

St. Olave's Hospital, London, S.E.16.

The CONDITION now known as regional ileitis was established as a clinical, radiological and pathological entity by Crohn, Ginzburg and Oppenheimer in 1932. The histological nature of this disease was further underlined by Hadfield in 1939. Regional ileitis was thus established as a disease of unknown ætiology, characterised by a thickened segment of ileum, consisting histologically of non-caseating granulomatous foci, together with a granulomatous involvement of the regional lymph nodes. Skip areas in the bowel were described as a typical feature of the condition.

This type of granulomatous condition affecting the ileum together with the colon (Crohn, 1949), and cases involving the colon alone (Armitage and Wilson, 1950), were later described. Regional ileitis, together with the involvement of the upper gastrointestinal tract was also reported (Rose 1949, Martin and Carr 1953, Richman, Seifer, Winkelstein, Kirschner and Steinhardt 1955, Miller, Sandweiss and Schwachmann 1956). Finally, cases have been described where this granulomatous condition affects the stomach alone.

Because of its comparative rarity and interest, a further case of isolated granulomatous gastritis is reported.

\section{Case Report}

Mr. W.F., a 57 year old caretaker, first presented at this hospital in August 1953. He gave a 15-year history of recurrent episodes of pain in the epigastrium and right hypochondrium. The pain would start one hour after a meal, persist for about 10 minutes and was occasionally associated with vomiting. He was tender in the epigastrium and

*Present address: The Lahey Clinic, Dept. of Surgery, 605 Commonwealth Avenue, Boston, U.S.A. right hypochondrium. There were no other abnormal physical signs. A barium meal and gastroscopy done at that time showed no abnormality.

Operation. While in hospital, he developed severe acute pain in the epigastrium. A tender gall-bladdef was palpable. At operation the gall-bladder was distended and contained stones. The common bilee duct was dilated and there was a large stone at its lower end. A cholecystectomy with choledocholithotomy was performed. He made an uneventful recovery.

Two months post-operatively his original symptoms of epigastric pain and vomiting recurred and persisted since.

Investigations. Over the next 7 years he was re-admitted to hospital on several occasions and followed regularly as an out-patient. The following is a summary of the investigations done over that interval :

July 1955 and

February 1956 Barium meals-No abnormality seen. November 1960 and

March 1961 Gastroscopies-No abnormality seen. May $1961 \quad$ Barium meal-There was a persistent irregularity of the lesser curvature of the stomach, near the pyloric antrum, probably an ulcer.

Because of his recurrent symptoms and barium meal findings, he was re-admitted in May 1961, for consideration of a further laparotomy. He was noted $\mathrm{N}$ to have clubbing of the fingers for the first time. There were no other abnormal physical signs.

Operation. At operation there were numerous adhesions present around the porta hepatis and in the upper abdomen generally, but otherwise no abnormality was found.

His symptoms persisted following this operation in spite of intensive medical treatment which included hospitalization and bed rest, antacids, antispasmodics, sedatives and tranquilizers.

Investigations. He was followed as an out-patient for the next two years and had a battery of in- 